\title{
High frequency jet ventilation through mask contributes to oxygen therapy among patients undergoing bronchoscopic intervention under deep sedation
}

\author{
Mingyuan Yang ${ }^{1}$, Bin Wang ${ }^{1}$, Qingwu Hou' ${ }^{1}$ Yunzhi Zhou ${ }^{2}, \mathrm{Na} \mathrm{Li}^{1}$, Hongwu Wang ${ }^{2}$, Lei Li ${ }^{1}$ and Qinghao Cheng ${ }^{1 *}$ (D)
}

\begin{abstract}
Background: High frequency jet ventilation (HFJV) is an open ventilating technique to maintain ventilation for emergency or difficult airway. However, whether jet ventilation or conventional oxygen therapy (COT) is more effective and safe in maintaining adequate oxygenation, is unclear among patients with airway stenosis during bronchoscopic intervention (BI) under deep sedation.

Methods: A prospective randomized cohort study was conducted to compare COT (high flow oxygen) with normal frequency jet ventilation (NFJV) and HFJV in oxygen supplementation during BI under deep sedation from March 2020 to August 2020. Patients receiving BI under deep sedation were randomly divided into 3 parallel groups of 50 patients each: the COT group (fractional inspired oxygen $\left(\mathrm{FiO}_{2}\right)$ of 1.0, $12 \mathrm{~L} / \mathrm{min}$ ), the NFJV group $\left(\mathrm{FiO}_{2}\right.$ of 1.0, driving pressure of $0.1 \mathrm{MPa}$, and respiratory rate (RR) $15 \mathrm{bpm}$ ) and the HFJV Group ( $\mathrm{FiO}_{2}$ of 1.0, driving pressure of $0.1 \mathrm{MPa}$, and RR of 1200 bpm). Pulse oxygen saturation $\left(\mathrm{SpO}_{2}\right)$, mean arterial blood pressure and heart rate were recorded during the whole procedure. Arterial blood gas was examined and recorded $15 \mathrm{~min}$ after the procedure was initiated. The procedure duration, dose of anesthetics, and adverse events during $\mathrm{Bl}$ in the three groups were also recorded.
\end{abstract}

Results: A total of 161 patients were enrolled, with 11 patients excluded. The clinical characteristics were similar among the three groups. $\mathrm{PaO}_{2}$ of the COT and NFJV groups was significantly lower than that of the HFJV group $(P<$ 0.001). $\mathrm{PaO}_{2}$ was significantly correlated with ventilation mode $(P<0.001)$, body mass index $(\mathrm{BMI})(P=0.019)$ and procedure duration $(P=0.001)$. Multiple linear regression showed that only $\mathrm{BMI}$ and procedure duration were independent influencing factors of arterial blood gas $\mathrm{PaO}_{2}(P=0.040$ and $P=0.002$, respectively). The location of airway lesions and the severity of airway stenosis were not statistically correlated with $\mathrm{PaCO}_{2}$ and $\mathrm{PaO}_{2}$.

Conclusions: HFJV could effectively and safely improve intra-operative $\mathrm{PaO}_{2}$ among patients with airway stenosis during $\mathrm{Bl}$ in deep sedation, and it did not increase the intra-operative $\mathrm{PaCO}_{2}$ and the risk of hypercapnia. $\mathrm{PaO}_{2}$ was correlated with ventilation mode, BMI and procedure duration. Only BMl and procedure duration were independent influencing factors of arterial blood gas $\mathrm{PaO}_{2}$. $\mathrm{PaCO}_{2}$ was not correlated with any preoperative factor.

\footnotetext{
*Correspondence: cqh4000@163.com

'Department of Anesthesiology, Emergency General Hospital, Beijing 100028,

China

Full list of author information is available at the end of the article
}

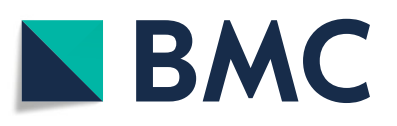

(- The Author(s). 2021 Open Access This article is licensed under a Creative Commons Attribution 4.0 International License, which permits use, sharing, adaptation, distribution and reproduction in any medium or format, as long as you give appropriate credit to the original author(s) and the source, provide a link to the Creative Commons licence, and indicate if changes were made. The images or other third party material in this article are included in the article's Creative Commons licence, unless indicated otherwise in a credit line to the material. If material is not included in the article's Creative Commons licence and your intended use is not permitted by statutory regulation or exceeds the permitted use, you will need to obtain permission directly from the copyright holder. To view a copy of this licence, visit http://creativecommons.org/licenses/by/4.0/ The Creative Commons Public Domain Dedication waiver (http://creativecommons.org/publicdomain/zero/1.0/) applies to the data made available in this article, unless otherwise stated in a credit line to the data. 
(Continued from previous page)

Trial registration: Chinese Clinical Trial Registry. Registration number, ChiCTR2000031110, registered on March $22,2020$.

Keywords: Bronchoscopic intervention, Conventional oxygen therapy, Normal frequency jet ventilation, High frequency jet ventilation

\section{Background}

Bronchoscopic intervention (BI) has become the preferred method for the diagnosis and treatment of airway lesions. It plays an important role in improving the patients' quality of life, especially by relieving airway obstructions [1]. Different procedures require different methods of anesthesia and different airway management. Various oxygen delivery routes include nasal catheters, face masks, laryngeal mask airway (LMA) and supraglottic tubes, such as Wei nasal jet tube, endotracheal tube, and rigid bronchoscope $[2,3]$. Endoscopic face mask is one of the most commonlyused oxygen-delivery devices for BI because of its high comfort and non-influence on bronchoscope insertion. Different ventilation modes, including conventional oxygen therapy (COT), intermittent ventilation, controlled mechanical ventilation, and jet ventilation could be utilized for conducting differentiated airway management, which have their own advantages and disadvantages [4-6].

Hypoxemia is a major complication and thus the main focus of anesthesia during deep sedation especially among patients undergoing $\mathrm{BI}[7,8]$. The main mechanisms of hypoxemia in BI are ventilation/blood flow imbalance and decreased ventilation in accordance with airway stenosis, especially after sedation. With the continuous development of modern medicine, the method for oxygen supply has changed, and the traditional oxygen therapy is no longer the classic and only method available. High-flow oxygen through nasal cannula or mask was used among patients infected with COVID-19 associated with severe hypoxemia, and it showed reductions in the need for therapeutic escalation and intubation among patients who received high-flow oxygen [9]. Supraglottic jet ventilation (SJV) is also superior to conventional means of oxygen delivery among patients with obesity who are under intravenous anesthesia [10].

High-frequency jet ventilation (HFJV) is believed to improve oxygenation of patients during $\mathrm{BI}$, but whether jet ventilation is superior to $\mathrm{COT}$ and normal-frequency jet ventilation (NFJV) in maintaining intra-operative oxygenation is unclear among patients with airway stenosis during BI under deep sedation. Specially, we evaluated the hypothesis that HFJV could improve intra-operative $\mathrm{PaO}_{2}$ among patients with airway stenosis during $\mathrm{BI}$ in deep sedation.

\section{Methods}

\section{Study design}

This prospective randomized study aims to assess the efficacy and safety of oxygen supplementation via three different ventilation modes including COT, NFJV, and HFJV, during BI under deep sedation.

This study was approved by the Medical Research Ethics Committee of Emergency General Hospital in Beijing, China (K20-9). All the patients or their relatives signed informed consent prior to the commencement of the study program. This study was registered in Chinese Clinical Trial Registry on March 22, 2020 (Registration number: ChiCTR2000031110). It also followed the Consolidated Standards of Reporting Trials (CONSORT) guidelines.

\section{Study population}

All patients were selected by the Center of BI, Emergency General Hospital, to undergo BI under deep sedation from March 2020 to August 2020. Inclusion criteria were as follows: (1) Scheduled for electric flexible bronchoscope; (2) Duration of operation, between 20 and $60 \mathrm{~min}$; (3) Age, 18-80 years. Exclusion criteria were as follows: (1) Diagnosed with cardiac respiratory failure and coma; (2) T-tube, endotracheal intubation, and tracheotomy, or $\mathrm{SpO}_{2}<90 \%$ in room air before the surgery; (3) History of mental and neurological disorders, sedative or hypnotic drugs and alcohol abuse; (4) Change of anesthesia method during the operation; (5) Intra-operative massive hemorrhage; (6) Patients transferred back to ICU with endotracheal intubation after operation.

In accordance with different ventilation modes, the eligible patients were randomized in a 1:1:1 ratio into three parallel groups by a physician unaware of the study. The three groups were the COT group, the NFJV group, and the HFJV group. To ensure blinding, the group allocation number was placed in an envelope, which the anesthesiologist opened preoperatively. A data investigator collected and recorded all perioperative data. The statistician and investigator were independent and blinded to the treatment.

BI procedures were advanced diagnostic and therapeutic procedures, which included laser, electrocautery, cryotherapy, balloon dilation, argon plasma coagulation and photodynamic therapy. All BI procedures were performed by experienced endoscopists using electric flexible bronchoscopy (Pentax, Japan). 


\section{Anesthetic settings and maintenance}

Upon the entrance to the operating room, patients underwent electrocardiogram (ECG), pulse oximetry $\left(\mathrm{SpO}_{2}\right)$, and blood pressure monitoring. Lidocaine $(1 \%$, $10 \mathrm{ml}$ ) was administered via the spray-as-you-go technique before intervention. An endoscopic face mask was provided for oxygenation. The total bolus dose of remifentanil $\left(40 \mu \mathrm{g} \cdot \mathrm{ml}^{-1}\right)$ was $1 \mu \mathrm{g} \cdot \mathrm{kg}^{-1}$ and $1 \mathrm{ml}$ was injected each time with an interval of $1 \mathrm{~min}$. Then, propofol (1 $\mathrm{mg} \cdot \mathrm{kg}^{-1}$ ) was injected $2 \mathrm{~min}$ after remifentanil was administered during the induction of anesthesia. Continuous injection of remifentanil $\left(0.10 \sim 0.15 \mu \mathrm{g} \cdot \mathrm{kg}^{-1} \cdot \mathrm{min}^{-1}\right)$ and propofol $\left(30 \sim 50 \mu \mathrm{g} \cdot \mathrm{kg}^{-1} \cdot \mathrm{min}^{-1}\right)$ by microinjection pumps was performed in accordance with the patient's vital signs. The fluctuation of the patient's mean arterial blood pressure (MAP) was controlled at $20 \%$ of the baseline. If the fluctuation of MAP was more than 20\%, the depth of anesthesia was adjusted or vasopressor was given. The patients maintained a Ramsey sedation scale (RSS) score of $3 \sim 4$. They breathed spontaneously during $\mathrm{BI}$. When the $\mathrm{SpO}_{2}$ value was $<95 \%$, the anesthesiologists increased the driving pressure by $0.05 \mathrm{MPa}$, and when the $\mathrm{SpO}_{2}$ value was $<90 \%$, the anesthesiologists performed mask-bag ventilation.

The oxygen for COT was provided at fractional inspired oxygen $\left(\mathrm{FiO}_{2}\right)$ of 1.0 with a flow rate of $12 \mathrm{~L} / \mathrm{min}$ through a ventilator (Drager, Germany). The oxygen for NFJV was provided at $\mathrm{FiO}_{2}$ of 1.0 with a driving pressure (DP) of $0.1 \mathrm{MPa}$, respiratory rate (RR) of $15 \mathrm{bpm}$, and I/ E ratio of 1:1.5 through jet ventilation (Twin Stream ${ }^{\mathrm{T}}$, Austria). The oxygen for HFJV was provided at $\mathrm{FiO}_{2}$ of 1.0 with a DP of $0.1 \mathrm{MPa}, \mathrm{RR}$ of $1200 \mathrm{bpm}$ and I/E ratio of 1:1.5 through jet ventilation (Twin Stream ${ }^{\mathrm{TM}}$, Austria).

\section{Data collection}

The location and severity of airway stenosis were recorded by the data recorder before BI. The location of airway lesions was divided into four types: 1) upper and middle parts of the main airway, 2) middle and lower parts of the main airway, 3) left or right main bronchial, and 4) distal bronchial. The severity of airway stenosis was graded to three levels: 1 for $0 \% \sim 59 \%, 2$ for $60 \%$ $89 \%$, and 3 for above $90 \%$. The following parameters were continuously monitored during anesthesia: $\mathrm{SpO}_{2}$, MAP, heart rate (HR) and ECG. Meanwhile, the patients' $\mathrm{SpO}_{2}, \mathrm{MAP}$ and $\mathrm{HR}$ were recorded at baseline $\left(\mathrm{T}_{0}\right)$, the beginning of procedure $\left(\mathrm{T}_{\mathrm{Beg}}\right), 15 \mathrm{~min}$ after the initiation of procedure $\left(\mathrm{T}_{15}\right)$, and the end of procedure $\left(\mathrm{T}_{\mathrm{End}}\right)$. Arterial blood gas (ABG) was examined and recorded $15 \mathrm{~min}$ after the initiation of procedure. The procedure duration and dose of anesthetics during BI in the three groups were also recorded. Adverse events including intra-operative hypoxemia $\left(\mathrm{SpO}_{2}<90 \%\right)$, intra-operative hypercapnia $\left(\mathrm{PCO}_{2} \geq 50 \mathrm{mmHg}\right)$, intra-operative severe hypercapnia $\left(\mathrm{PCO}_{2} \geq 100 \mathrm{mmHg}\right)$, post-operative hypoxemia $\left(\mathrm{SpO}_{2}<90 \%\right)$, post-operative hypercapnia $\left(\mathrm{PCO}_{2} \geq\right.$ $50 \mathrm{mmHg})$, post-operative severe hypercapnia $\left(\mathrm{PCO}_{2} \geq\right.$ $100 \mathrm{mmHg}$ ), and post-operative agitation, were recorded by data investigator. The primary outcomes were $\mathrm{PaO}_{2}$ among three groups and its influencing factors, and the secondary outcomes were $\mathrm{PaCO}_{2}$ among three groups and its influencing factors.

\section{Statistical analysis}

$\mathrm{PaO}_{2}$ was seen as the primary outcome in this study. The mean \pm standard deviation (SD) of $\mathrm{PaO}_{2}$ was $164.0 \pm 73.4 \mathrm{mmHg}, \quad 220.2 \pm 86.5 \mathrm{mmHg}, \quad$ and $210.2 \pm$ $65.1 \mathrm{mmHg}$ of the COT, NFJV and HFJV groups according to a pilot study of 5 patients, respectively. The sample size was estimated by the formula of $n=\left(\mu_{\alpha}+\mu_{\beta}\right)^{2} \sigma^{2}$ / $\delta^{2}$ with a standard deviation of 0.8 , and bilaterally equal to 0.05 , or even 0.2 (power $=0.8$ ). We thus calculated to enroll 35 patients in each group.

SPSS 20.0 software was used for data collation and statistical analysis. The continuous data were expressed as mean $\pm \mathrm{SD}$, and the counting data were presented as the number and percentage. Chi-square test was used to compare the counting data of different groups (the $P$ value was directly calculated using Fisher's exact probability method if necessary). Univariate analysis of variance (ANOVA) was used for overall comparison among groups, and least significance difference (LSD) was used for multiple comparison between groups. Pearson analysis was used to investigate the correlation between blood gas indicators of $\mathrm{PaO}_{2}$ and $\mathrm{PaCO}_{2}$ and the clinical characteristics of patients. Multiple linear regression analysis was used to explore the independent influencing factors of $\mathrm{PaO}_{2}$ and $\mathrm{PaCO}_{2} . P<0.05$ was considered statistically significant.

\section{Results}

A total of 161 patients were enrolled. Three patients in the COT group, four patients in the NFJV group and another four patients in the HFJV group were excluded because of change to rigid bronchoscope and general anesthesia during operation. All the remaining patients tolerated the BI well (Fig. 1). Two patients in the COT group (lowest $\mathrm{SpO}_{2}$ values were 79 and $85 \%$, lasting for $2 \mathrm{~min}$ and $1 \mathrm{~min}$ ), three patients in the NFJV group (lowest $\mathrm{SpO}_{2}$ values were 81,83 , and $87 \%$, lasting for $1 \mathrm{~min}$, $1 \mathrm{~min}$, and $2 \mathrm{~min}$, respectively) and two patients in the HFJV group (lowest $\mathrm{SpO}_{2}$ values were 87 and $88 \%$, both lasting for $1 \mathrm{~min}$ ) developed hypoxemia. No other adverse events such as severe hypercapnia and postoperative agitation occurred.

The clinical characteristics of patients are represented in Table 1. No significant differences were found among the three groups in terms of age, height, weight, body 


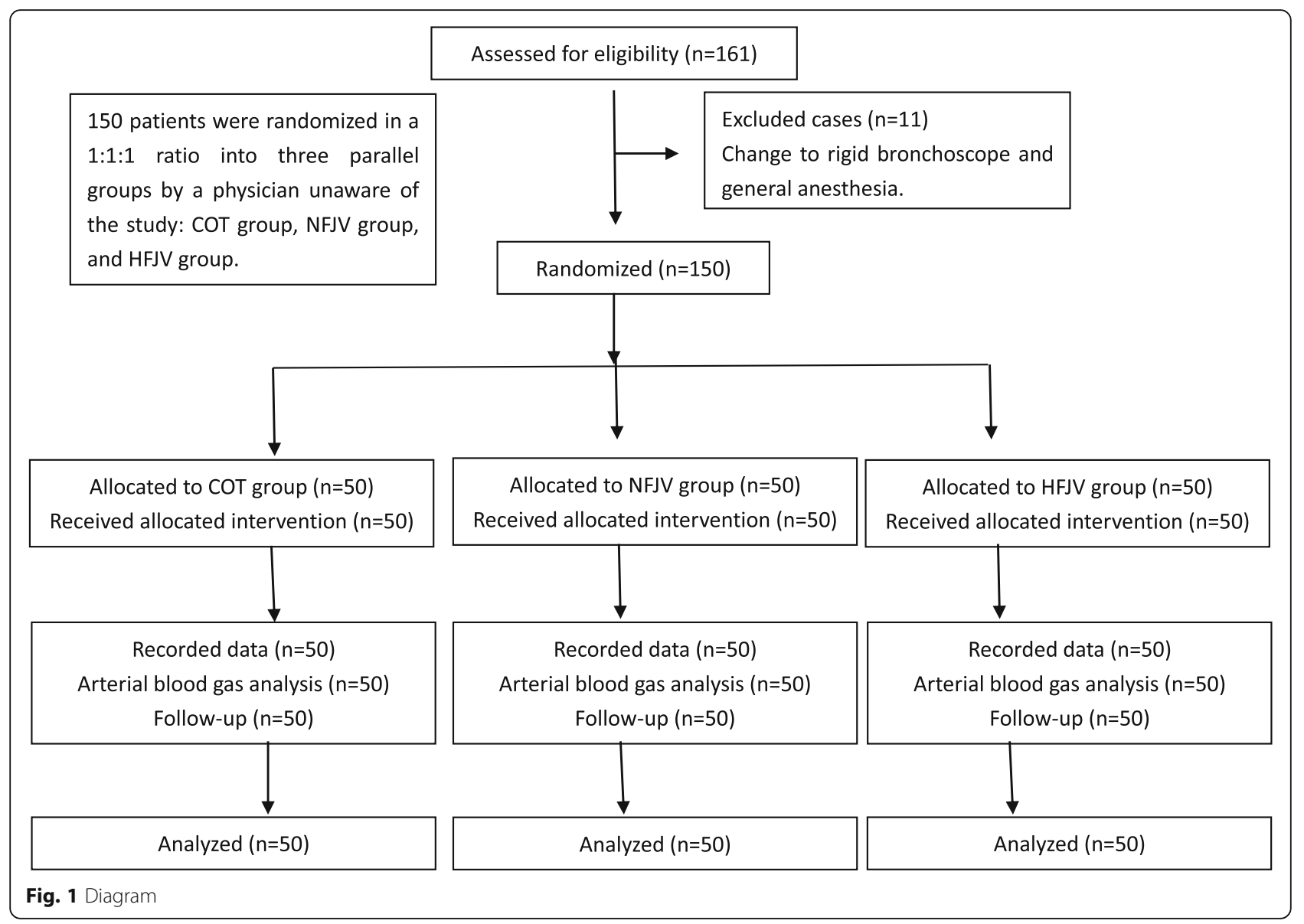

mass index (BMI), gender, pathological type, ASA classification, lesion site and stenosis degree. However, significant differences were observed among the three groups in terms of the following comorbidities: cerebrovascular disease, other tumors (such esophageal cancer and thyroid cancer), and chronic lung disease (including tuberculosis pneumonia, and COPD). The number of patients with cerebrovascular disease in the COT group was significantly higher than that in the NFJV and HFJV groups $(P=0.011)$. The number of patients with other tumors in the NFJV group was significantly higher than that in the HFJV group $(P=0.029)$. The number of patients with chronic lung disease in the COT group was significantly higher than that in the NFJV group $(P=0.017)$.

The blood gas values and procedure duration are shown in Table 2. $\mathrm{PaO}_{2}$, lactic acid and procedure duration significantly differed among the three groups $(P<0.001, P=0.005$, and $P=0.038$, respectively). The $\mathrm{PaO}_{2}$ in the HFJV group was significantly higher than that in the COT and NFJV groups. Moreover, the lactic acid in the HFJV group was significantly higher and procedure duration was significantly longer. No significant differences in $\mathrm{PaCO}_{2}$, blood glucose and pondus hydrogenii $(\mathrm{PH})$ were found among the three groups.

The MAP, HR, and $\mathrm{SpO}_{2}$ of each period time (Fig. 2) and anesthetic dose (Fig. 3) among the three groups did not significantly differ.

All peri-operative related factors associated with $\mathrm{PaO}_{2}$ were detected via Pearson analysis. The result showed that $\mathrm{PaO}_{2}$ was significantly correlated with ventilation mode $(P<0.001)$, BMI $(P=0.019)$ and procedure duration $(P=0.001)$. The ASA level, location of airway lesions, and severity of airway stenosis had no statistical correlation with $\mathrm{PaO}_{2}$. Multiple linear regression showed that $\mathrm{BMI}$ and procedure duration were independent influencing factors $(P=0.040, P=0.002)$, while ventilation mode was not an independent factor. The details are shown in Tables 3 and 4.

All the factors associated with $\mathrm{PaCO}_{2}$ were also detected via Pearson analysis, as shown in Table 5. No statistical correlation was found between blood gas $\mathrm{PaCO}_{2}$ and ventilation mode, lesion location, stenosis degree, and procedure duration. Multiple linear regression demonstrated that the above indices were not independent influencing factors of blood gas $\mathrm{PaCO}_{2}$, as shown in Table 6 . 
Table 1 Comparison of preoperative patient characteristics among three groups

\begin{tabular}{|c|c|c|c|c|}
\hline Characteristic & Group COT $(n=50)$ & Group NFJV(n=50) & Group HFJV(n= 50) & $P$ Value \\
\hline Age, mean $\pm S D$, years & $49.1 \pm 14.4$ & $54.2 \pm 15.5$ & $51.6 \pm 14.4$ & 0.227 \\
\hline Height,mean \pm SD, $(\mathrm{cm})$ & $165.0 \pm 7.7$ & $167.2 \pm 7.1$ & $167.0 \pm 8.7$ & 0.316 \\
\hline Weight, mean \pm SD, (Kg) & $61.3 \pm 8.3$ & $63.5 \pm 11.0$ & $63.6 \pm 10.3$ & 0.423 \\
\hline Body Mass Index, mean \pm SD(\%) & $22.6 \pm 3.4$ & $22.7 \pm 3.4$ & $22.7 \pm 2.7$ & 0.976 \\
\hline Male, n (\%) & $33(66)$ & $32(64)$ & $34(68)$ & 0.915 \\
\hline ASA score & & & & 0.157 \\
\hline Classl, n (\%) & $0(0)$ & $0(0)$ & $2(4)$ & \\
\hline Classll, n (\%) & $20(40)$ & $26(52)$ & $27(54)$ & \\
\hline Class III, n (\%) & $30(60)$ & $24(48)$ & $21(42)$ & \\
\hline \multicolumn{5}{|l|}{ Comorbidities } \\
\hline Cardiovascular history, n (\%) & $9(18)$ & $12(24)$ & $11(22)$ & 0.757 \\
\hline Cerebrovascular disease, n (\%) & $5(10)^{b c}$ & $0(0)^{a}$ & $0(0)^{a}$ & 0.011 \\
\hline Other tumors, n (\%) & $5(10)$ & $9(18)^{c}$ & $1(2)^{b}$ & 0.029 \\
\hline Diabetes mellitus, n (\%) & $3(6)$ & $6(12)$ & $10(20)$ & 0.108 \\
\hline Chronic pulmonary disease, n (\%) & $6(12)^{c}$ & $0(0)^{a}$ & $1(2)$ & 0.017 \\
\hline Tracheal esophageal fistula, n (\%) & $1(2)$ & $2(4)$ & $5(10)$ & 0.277 \\
\hline Lobectomy, n (\%) & $10(20)$ & $6(12)$ & $6(12)$ & 0.426 \\
\hline \multicolumn{5}{|l|}{ Pathology } \\
\hline Non-tumor, n (\%) & $20(40)$ & $23(46)$ & $18(36)$ & 0.592 \\
\hline Tumor, n (\%) & $30(60)$ & $27(54)$ & $32(64)$ & 0.592 \\
\hline lesion location & & & & 0.074 \\
\hline Upper main airway, n (\%) & $17(34)$ & $14(28)$ & $10(20)$ & \\
\hline Lower main airway, n (\%) & $12(24)$ & $22(44)$ & $16(32)$ & \\
\hline Left and right bronchus, n (\%) & $8(16)$ & $10(20)$ & $9(18)$ & \\
\hline Others, n (\%) & $13(26)$ & $4(8)$ & $15(30)$ & \\
\hline Degree of stenosis & & & & 0.837 \\
\hline 0-59\%, n (\%) & $28(56)$ & $33(66)$ & $32(64)$ & \\
\hline $60-89 \%, n(\%)$ & $12(24)$ & $10(20)$ & $9(18)$ & \\
\hline$\geq 90 \%, n(\%)$ & $10(20)$ & $7(14)$ & $9(18)$ & \\
\hline
\end{tabular}

Data were expressed as mean \pm standard deviation or as numbers and percentages. ${ }^{\text {a }}$ was statistically significant compared with COT group, ${ }^{\mathrm{b}}$ was statistically significant compared with HFJV group, ${ }^{c}$ was statistically significant compared with NFJV group

The number of patients with cerebrovascular disease in the COT group was significantly higher than that in the NFJV and HFJV groups $(P=0.011)$. The number of patients with other tumors (including esophageal cancer, thyroid cancer, etc) in the NFJV group was significantly higher than that in the HFJV group ( $P=0.029)$. The number of patients with chronic lung disease (including tuberculosis pneumonia, COPD, etc) in the COT group was significantly higher than that in the NFJV group $(P=0.017)$

COT conventional oxygen therapy; NFJV normal frequency jet ventilation; HFJV high frequency jet ventilation

\section{Discussion}

BI has shown remarkable advancements in pulmonary medicine diagnostics and therapy in recent years. Monitored anesthesia care (MAC) is performed in basic and some advanced BI [11]. By maintaining spontaneous breathing, without the need for LMA or intubation, MAC could meet the surgical needs and alleviates the patients' discomfort [1]. The commonly used ventilation modes included COT, intermittent ventilation, controlled mechanical ventilation, and jet ventilation (manual or automatic, high or normal frequency) $[11,12]$. Ventilation mode is the most direct factor affecting the oxygenation of patients, especially in MAC $[6,13]$. In the present study, endoscopic face mask and three ventilation modes were used to provide oxygen to patients [14].

HFJV has become a technique for maintaining ventilation developed by Klain and Smith [5, 6]. Gas enters the breathing path at low pressure through a narrow jet tube. Open system, high frequency and low tide are the three characteristics of HFJV. This technique has become one of the most important ventilation modes in airway management, especially in the ASA guidelines for interventional pulmonology procedures [7]. In the present study, the effect of oxygenation maintenance in COT, 
Table 2 Blood gas values and procedure duration among three groups

\begin{tabular}{|c|c|c|c|c|}
\hline Patients values & Group COT $(n=50)$ & Group NFJV $(n=50)$ & Group HFJV $(n=50)$ & $P$ Value \\
\hline $\mathrm{PaO}_{2}(\mathrm{mmHg})$ & $176.3 \pm 73.4^{b}$ & $192.0 \pm 88.4^{b}$ & $251.7 \pm 86.6^{\mathrm{ac}}$ & $<0.001$ \\
\hline $\mathrm{PaCO}_{2}(\mathrm{mmHg})$ & $59.2 \pm 15.2$ & $59.8 \pm 14.1$ & $59.6 \pm 10.7$ & 0.972 \\
\hline Pondus hydrogenii & $7.3 \pm 0.1$ & $7.3 \pm 0.1$ & $7.3 \pm 0.1$ & 0.647 \\
\hline Glucose $(\mathrm{mmol} / \mathrm{l})$ & $6.4 \pm 1.8$ & $6.9 \pm 1.9$ & $7.0 \pm 2.1$ & 0.203 \\
\hline Lactic acid (mmol/l) & $1.1 \pm 0.4^{\mathrm{b}}$ & $1.4 \pm 0.7$ & $1.6 \pm 1.1^{\mathrm{a}}$ & 0.005 \\
\hline Procedure duration (min) & $27.9 \pm 8.8^{b}$ & $29.3 \pm 8.5$ & $33.0 \pm 12.7^{\mathrm{a}}$ & 0.038 \\
\hline
\end{tabular}

${ }^{*}$ Data were presented as mean \pm standard deviation (median, range). ${ }^{a}$ was statistically significant compared with COT group, ${ }^{\mathrm{b}}$ was statistically significant compared with HFJV group, ${ }^{c}$ was statistically significant compared with NFJV group

There were significant differences among the three groups in $\mathrm{PaO}_{2}$, lactic acid and procedure duration $(P<0.001, P=0.005, P=0.038)$. Moreover, PaO , of $\mathrm{HFJV}$ group was significantly higher than that of COT and NFJV group. Lactic acid and procedure duration of HFJV group was significantly higher than that of COT group COT conventional oxygen therapy; NFJV normal frequency jet ventilation; HFJV high frequency jet ventilation

NFJV, and HFJV was compared via face mask during BI under MAC. The $\mathrm{PaO}_{2}$ in the HFJV group increased to $251.7 \mathrm{mmHg}$, higher than that in the COT and NFJV groups. HFJV has certain PEEP effects, which can open the airway, reduce the anatomical inefficiency of the nasopharyngeal cavity, improve the final expiratory volume of the lung, and increase the effective ventilation of the alveoli $[15,16]$. The $\mathrm{PaO}_{2}$ in the NFJV group was 192.0 $\mathrm{mmHg}$, higher than that in the COT group (176.3 $\mathrm{mmHg}$ ), but no statistical difference was found. The mechanism of NFJV was similar with that of HFJV. In addition, NFJV may cause asynchronous breathing, resulting in less significant oxygenation improvement than that in HFJV. The results indicated that HFJV is an effective and safe oxygen supplementation for patients under MAC in BI.

In addition to $\mathrm{PaO}_{2}$, another point of concern was the patient's $\mathrm{PaCO}_{2}$. A previous review proved that NFJV was more suitable for BI than HFJV, which may cause $\mathrm{CO}_{2}$ accumulation when jet frequency was above 150/ min [17]. The $\mathrm{PaCO}_{2}$ values in the COT, NFJV, and HFJV groups were $59.2 \mathrm{mmHg}, 59.8 \mathrm{mmHg}$ and 59.6 $\mathrm{mmHg}$, respectively, and no significant difference was found among them. Although the $\mathrm{PaCO}_{2}$ value was
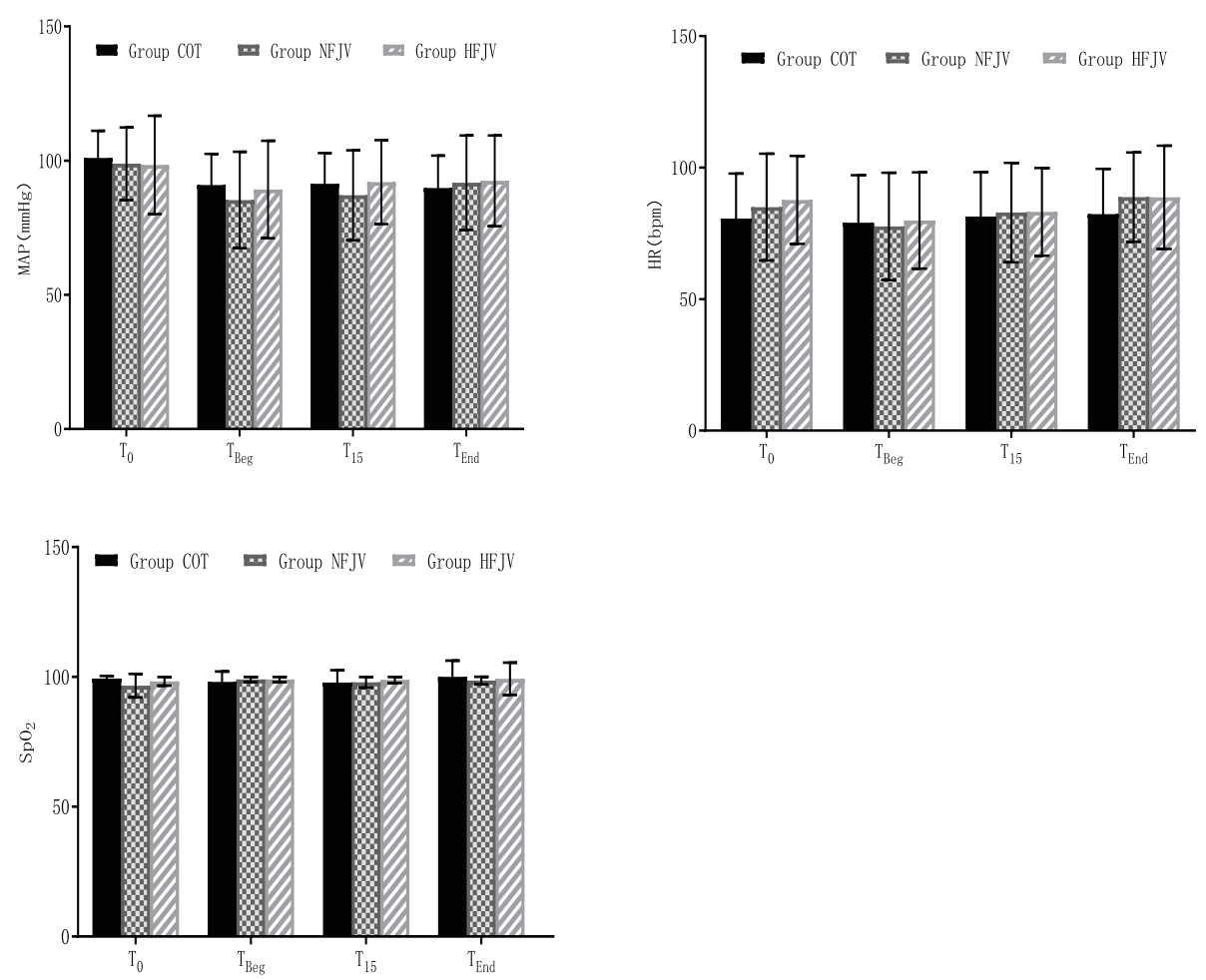

Fig. 2 Hemodynamic indexes among three groups. No significant differences among three groups in MAP, HR and $\mathrm{SpO}_{2}$ at different time points. Patients' $\mathrm{SpO}_{2}, \mathrm{MBP}$ and $\mathrm{HR}$ were recorded at baseline $\left(\mathrm{T}_{0}\right)$, beginning of procedure $\left(T_{\text {Beg }}\right), 15$ min after initiation of procedure $\left(T_{15}\right)$, and at the end of procedure $\left(T_{\text {End }}\right)$. COT: conventional oxygen therapy; NFJV: normal frequency jet ventilation; HFJV: high frequency jet ventilation 

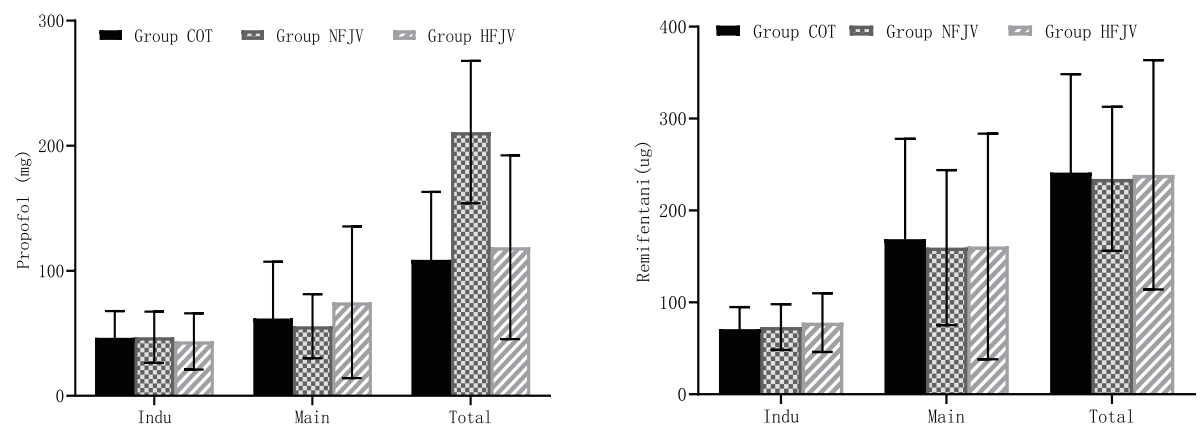

Fig. 3 Anesthetic doses among the three groups. No significant differences among three groups in propofol and remifentanil at different periods. Induction (Indu), maintenance (Main) and total (Total) dose of anesthetics during bronchoscopic intervention in the three groups were recorded. COT: conventional oxygen therapy; NFJV: normal frequency jet ventilation; HFJV: high frequency jet ventilation

higher than the upper limit of the normal value, no delayed awakening occurred. Pearson analysis showed no important factors affecting $\mathrm{PaCO}_{2}$ and certainly no independent factors, either. Mild hypercapnia may not cause brain injury and only worsen the condition of the brain when $\mathrm{PaCO}_{2}$ is above $100 \mathrm{mmHg}[8,18,19]$. Thus anesthesiologists did not provide any treatment when the $\mathrm{PaCO}_{2}$ was a little above $50 \mathrm{mmHg}$.

Intraoperative oxygenation of patients might be affected by many factors. In this study, multiple linear regression showed that only BMI and procedure duration were independent influencing factors of $\mathrm{PaO}_{2}$, and there was no independent influencing factors of $\mathrm{PaCO}_{2}$. The key of MAC in BI is how to maintain the patients' oxygenation in open airway and ensure the feasibility of the procedures. Pathological airways often cause restricted ventilation dysfunction, resulting in decreased respiratory power, increased elastic resistance, decreased alveolar compliance, and limited lung expansion, which are all important factors affecting $\mathrm{PaO}_{2}$ [4]. Meanwhile, the extent and location of the lesions as well

Table 3 Pearson analysis of blood gas $\mathrm{PaO}_{2}$ related factors

\begin{tabular}{lll}
\hline Characteristic & $\mathbf{F}$ & $\boldsymbol{P}$ \\
\hline Group COT/NFJV/HFJV & 11.5 & $<\mathbf{0 . 0 0 1}$ \\
Body mass index & -0.2 & $\mathbf{0 . 0 1 9}$ \\
Procedure duration & 0.3 & $\mathbf{0 . 0 0 1}$ \\
ASA score & 2.0 & 0.143 \\
Lesion location & 2.2 & 0.092 \\
Degree of stenosis & 2.3 & 0.101 \\
\hline
\end{tabular}

Pearson analysis showed that $\mathrm{PaO}_{2}$ was significantly correlated with ventilation mode, body mass index and procedure duration COT conventional oxygen therapy; NFJV normal frequency jet ventilation; HFJV high frequency jet ventilation

Lesions location: 1) the upper and middle part of the main airway, 2) the middle and lower part of the main airway, 3) the left or right main bronchial and 4) in the distal bronchial. Degree of stenosis: 1 for $0-59 \%, 2$ for $60-89 \%$, and 3 for above $90 \%$ as whether the open airway aggravates its effect on $\mathrm{PaO}_{2}$, are problems worth solving. In the present study, the location of airway lesions (which was divided into four types) and the severity of airway stenosis (which was graded into three levels), were speculated to be the important factors related to $\mathrm{PaO}_{2}$. However, Pearson analysis showed that both were not important factors affecting $\mathrm{PaO}_{2}$, and certainly were not independent factors.

In this research, the incidence of adverse events was lower than that previous reported $[10,20]$. Among the 150 patients, only seven developed intra-operative hypoxemia, which was relatively short and the oxygenation was effectively improved after treatment. Hypoxemia mainly occurred at two stages: one was after induction of anesthesia and the other was in the period of balloon dilation. Rapid anesthesia induction may lead to respiratory depression, as manifested by decreasing RR and tidal volume, the absence of spontaneous breathing and even the occurrence of apnea. $\mathrm{SpO}_{2}$ was effectively returned to normal after the anesthesiologist reduced the depth of anesthesia to restore spontaneous breathing or with the assistance of bag-mask ventilation. Balloon dilatation resulted in transient complete airway obstruction. After balloon dilatation, normal ventilation could be restored, and $\mathrm{SpO}_{2}$ could quickly return to normal [21, 22].

Table 4 Multiple linear regression analysis of blood gas $\mathrm{PaO}_{2}$ related factors

\begin{tabular}{|c|c|c|c|}
\hline Variables & $\begin{array}{l}\text { Regression } \\
\text { coefficient }\end{array}$ & $\begin{array}{l}95 \% \text { Confidence } \\
\text { interval }\end{array}$ & $P$ Value \\
\hline Body mass index & -4.6 & $(-9.0,-0.2)$ & 0.040 \\
\hline Procedure duration & 2.1 & $(0.8,3.5)$ & 0.002 \\
\hline Group COT/NFJV/HFJV & 6.5 & $(-10.3,23.3)$ & 0.447 \\
\hline
\end{tabular}

Multiple linear regression results showed that body mass index and procedure duration were independent influencing factors of blood gas $\mathrm{PaO}_{2}$ respectively COT conventional oxygen therapy; NFJV normal frequency jet ventilation; HFJV high frequency jet ventilation 
Table 5 Pearson analysis of blood gas $\mathrm{PaCO}_{2}$ related factors

\begin{tabular}{lll}
\hline Characteristic & $\mathbf{F}$ & $\mathbf{P}$ \\
\hline Group COT/NFJV/HFJV & $<0.1$ & 0.972 \\
Body mass index & 0.1 & 0.351 \\
Procedure duration & $<0.1$ & 0.601 \\
ASA score & 0.5 & 0.616 \\
Lesion location & 0.2 & 0.869 \\
Degree of stenosis & 0.7 & 0.491
\end{tabular}

Pearson analysis showed that there was no statistical correlation between blood gas $\mathrm{PaCO}_{2}$ and ventilation mode, ASA classification, lesion location, stenosis degree, body mass index and procedure duration

COT conventional oxygen therapy; NFJV normal frequency jet ventilation; HFJV high frequency jet ventilation

Lesions location: 1) the upper and middle part of the main airway, 2) the middle and lower part of the main airway, 3) the left or right main bronchial and 4 ) in the distal bronchial. Degree of stenosis: 1 for $0-59 \%, 2$ for $60-89 \%$, and 3 for above $90 \%$

Many deficiencies in this study deserve further research. First, the dose and speed of anesthetic administration during MAC determined the depth of anesthesia and the degree of respiratory depression which determined $\mathrm{PaO}_{2}$ directly. No statistically significant difference was found in the anesthetic doses among the three groups. However, $\mathrm{PaO}_{2}$ may still be affected due to the differences in the patients' conditions and the operating habits of the anesthesiologists. Second, the ABG collection time was set at $15 \mathrm{~min}$ after the operation, when the patient was basically in a stable state of anesthesia. At this time, the airway obstruction was mostly treated already. Finally, only the sedation score of 3-4 was recorded. Bispectral index and neuromonitoring were not performed.

\section{Conclusion}

Compared with COT and NFJV, HFJV via endoscopic face mask could improve the intra-operative $\mathrm{PaO}_{2}$ in

Table 6 Multiple linear regression analysis of blood gas $\mathrm{PaCO}_{2}$ related factors

\begin{tabular}{llll}
\hline Variables & $\begin{array}{l}\text { Regression } \\
\text { coefficient }\end{array}$ & $\begin{array}{l}\text { 95\% Confidence } \\
\text { interval }\end{array}$ & $\boldsymbol{P}$ Value \\
\hline Body mass index & 0.3 & $(-0.4,1.0)$ & 0.425 \\
Procedure duration & 0.1 & $(-0.1,0.3)$ & 0.438 \\
Group COT/NFJ/HFJV & 0.2 & $(-2.6,2.9)$ & 0.905 \\
Lesion location & -0.4 & $(-2.5,1.7)$ & 0.714 \\
Degree of stenosis & -2.0 & $(-4.9,1.0)$ & 0.194 \\
\hline
\end{tabular}

The above indexes are not independent influencing factors of blood gas $\mathrm{PaCO}_{2}$

COT conventional oxygen therapy; NFJV normal frequency jet ventilation; HFJV high frequency jet ventilation

Lesions location: 1) the upper and middle part of the main airway, 2) the middle and lower part of the main airway, 3) the left or right main bronchial and 4) in the distal bronchial. Degree of stenosis: 1 for $0-59 \%, 2$ for $60-89 \%$, and 3 for above $90 \%$ patients with airway stenosis more effectively and safely during basic and some advanced BI in deep sedation. $\mathrm{PaO}_{2}$ was correlated with ventilation mode, BMI and procedure duration. BMI and procedure duration were independent influencing factors of arterial blood gas $\mathrm{PaO}_{2} \cdot \mathrm{PaCO}_{2}$ was not correlated with ventilation mode and other preoperative factors, which were not independent influencing factors either.

\section{Abbreviations}

COT: Conventional oxygen therapy; NFJV: Normal frequency jet ventilation; HFJV: High frequency jet ventilation; BI: Bronchoscopic intervention; RR: Respiratory rate; LMA: Laryngeal mask airway; SJV: Supraglottic jet ventilation; ECG: Electrocardiogram; $\mathrm{SpO}_{2}$ : Pulse oximetry; RSS: Ramsey Sedation $\mathrm{Scale}_{2} \mathrm{FiO}_{2}$ : Fractional inspired oxygen; DP: Driving pressure; MBP: Mean blood pressure; HR: Heart rate; ABG: Arterial blood gas; ANOVA: Univariate analysis of variance; LSD: Least significance difference; BMI: Body mass index; MAC: Monitored anesthesia care

\section{Acknowledgements}

Not applicable.

\section{Authors' contributions}

Study conception: HW, YZ, QC. Study design: MY, LL, HW, QC. Study conduct: MY, BW, QH, NL, YZ. Data analysis: MY. Data interpretation: MY, YZ, HW, QC. Drafting of the manuscript: MY, QC. All authors approved the final version of the manuscript.

\section{Funding}

The authors declare that they have no funding.

\section{Availability of data and materials}

The datasets used and/or analyzed during the current study are available from the corresponding author.

\section{Ethics approval and consent to participate}

This study was approved by the Medical Research Ethics Committee of Emergency General Hospital in Beijing, China (K20-9). All the patients or their relatives signed informed consent prior to the commencement of the study program.

\section{Consent for publication}

Not applicable.

\section{Competing interests}

All authors have no potential competing interests to declare.

\section{Author details}

${ }^{1}$ Department of Anesthesiology, Emergency General Hospital, Beijing 100028, China. ${ }^{2}$ Department of Pulmonary and Critical Care Medicine, Emergency General Hospital, Beijing, China.

Received: 12 August 2020 Accepted: 17 February 2021

Published online: 02 March 2021

\section{References}

1. Galway U, Zura A, Khanna S, Wang M, Turan A, Ruetzler K. Anesthetic considerations for bronchoscopic procedures: a narrative review based on the Cleveland Clinic experience. J Thorac Dis. 2019;11(7):3156-70.

2. Krecmerova M, Schutzner J, Michalek P, Johnson P, Vymazal T. Laryngeal mask for airway management in open tracheal surgery-a retrospective analysis of 54 cases. J Thorac Dis. 2018;10(5):2567-72.

3. Thiruvenkatarajan V, Dharmalingam A, Arenas G, Wahba M, Steiner R, Kadam VR, Tran A, Currie J, Van Wijk R, Quail A, et al. High-flow nasal cannula versus standard oxygen therapy assisting sedation during endoscopic retrograde cholangiopancreatography in high risk cases (OTHER): study protocol of a randomised multicentric trial. Trials. 2020;21(1):444.

4. Zhao H, Wang H, Sun F, Lyu S, An Y. High-flow nasal cannula oxygen therapy is superior to conventional oxygen therapy but not to noninvasive 
mechanical ventilation on intubation rate: a systematic review and metaanalysis. Crit Care. 2017;21(1):184.

5. Galmen K, Harbut P, Freedman J, Jakobsson JG. The use of highfrequency ventilation during general anaesthesia: an update. F1000Research. 2017;6:756.

6. Hohenforst-Schmidt W, Zarogoulidis P, Huang H, Man YG, Laskou S, Koulouris C, Giannakidis D, Mantalobas S, Florou MC, Amaniti A, et al. A new and safe mode of ventilation for interventional pulmonary medicine: the ease of nasal superimposed high frequency jet ventilation. J Cancer. 2018; 9(5):816-33.

7. de Lima A, Kheir F, Majid A, Pawlowski J. Anesthesia for interventional pulmonology procedures: a review of advanced diagnostic and therapeutic bronchoscopy. Can J Anaesth. 2018;65(7):822-36.

8. Cheng Q, Zhang J, Wang H, Zhang R, Yue Y, Li L. Effect of acute Hypercapnia on outcomes and predictive risk factors for complications among patients receiving Bronchoscopic interventions under general anesthesia. PLoS One. 2015;10(7):e0130771.

9. Whittle JS, Pavlov I, Sacchetti AD, Atwood C, Rosenberg MS. Respiratory support for adult patients with COVID-19. J Am Col Emerge Phys Open. 2020;1(2):95-101.

10. Liang H, Hou Y, Sun L, Li Q, Wei H, Feng Y. Supraglottic jet oxygenation and ventilation for obese patients under intravenous anesthesia during hysteroscopy: a randomized controlled clinical trial. BMC Anesthesiol. 2019; 19(1):151.

11. Chadha M, Kulshrestha M, Biyani A. Anaesthesia for bronchoscopy. Indian J Anaesthesia. 2015;59(9):565-73.

12. Fadaizadeh L, Hoseini MS, Bagheri M. Anaesthesia management during interventional Bronchoscopic procedures: laryngeal mask airway or rigid bronchoscope. Turkish J Anaesthesiol Reanimation. 2014;42(6):302-7.

13. Fuehner T, Fuge J, Jungen M, Buck A, Suhling H, Welte T, Gottlieb J, Greer M. Topical nasal anesthesia in flexible bronchoscopy--a cross-over comparison between two devices. PLoS One. 2016;11(3):e0150905.

14. Nisi F, Galzerano A, Cicchitto G, Puma F, Peduto VA. Improving patient safety after rigid bronchoscopy in adults: laryngeal mask airway versus face mask - a pilot study. Med Devices. 2015;8:201-6.

15. Helviz Y, Einav S. A systematic review of the high-flow nasal cannula for adult patients. Crit Care. 2018;22(1):71.

16. Bialka S, Copik M, Rybczyk K, Owczarek A, Jedrusik E, Czyzewski D, Filipowski M, Rivas E, Ruetzler K, Szarpak L, et al. Assessment of changes of regional ventilation distribution in the lung tissue depending on the driving pressure applied during high frequency jet ventilation. BMC Anesthesiol. 2018;18(1):101.

17. Putz L, Mayne A, Dincq AS. Jet ventilation during rigid bronchoscopy in adults: a focused review. Biomed Res Int. 2016;2016:4234861.

18. Cheng $Q$, Li L, Yang M, Sun L, Li R, Huang R, Ma J. Moderate hypercapnia may not contribute to postoperative delirium in patients undergoing bronchoscopic intervention. Medicine. 2019;98(22):e15906.

19. Cheng $Q$, Li L, Lin D, Li R, Yue Y, Wei H, Ma J. Effects of acute hypercapnia on cognitive function in patients undergoing bronchoscope intervention. J Thorac Dis. 2019;11(3):1065-71.

20. Chung SM, Choi JW, Lee YS, Choi JH, Oh JY, Min KH, Hur GY, Lee SY, Shim $\mathrm{J}$, Kang KH. Clinical effectiveness of high-flow nasal cannula in Hypoxaemic patients during Bronchoscopic procedures. Tuberculosis Respiratory Dis. 2019:82(1):81-5.

21. Pawlowski J. Anesthetic considerations for interventional pulmonary procedures. Curr Opin Anaesthesiol. 2013;26(1):6-12.

22. Sarkiss M. Anesthesia for bronchoscopy and interventional pulmonology: from moderate sedation to jet ventilation. Curr Opin Pulm Med. 2011;17(4):274-8.

\section{Publisher's Note}

Springer Nature remains neutral with regard to jurisdictional claims in published maps and institutional affiliations.

Ready to submit your research? Choose BMC and benefit from:

- fast, convenient online submission

- thorough peer review by experienced researchers in your field

- rapid publication on acceptance

- support for research data, including large and complex data types

- gold Open Access which fosters wider collaboration and increased citations

- maximum visibility for your research: over $100 \mathrm{M}$ website views per year

At BMC, research is always in progress.

Learn more biomedcentral.com/submissions 